\title{
PENSANDO E VIVENDO A ORIENTAÇÃO PROFISSIONAL
}

DOI: $10.22289 / 2446-922 X . V 5 S 1 A 3$

\section{Maisa Ribeiro de Magalhães ${ }^{1}$ \\ Bráulio Emílio Maciel Faria \\ Résia Silva de Morais}

\section{LUCCHIARI, D. H. (1993). PENSANDO E VIVENDO A ORIENTAÇÃO PROFISSIONAL. SÃO PAULO: SUMMUS.}

A obra Pensando e Vivendo a Orientação Profissional foi organizada pela autora Dulce Helena Penna Soares Lucchiari, livro é constituído de duas partes, a primeira de textos que apresentam a Orientação Profissional em sua prática com técnicas, planejamentos e uso do psicodrama. E a segunda parte de contextos, que difunde a Orientação profissional em quadros sociais, políticos e econômicos.

No primeiro capítulo ressalta dificuldade que os jovens possuem para realizar suas escolhas profissionais. Em prol desse aspecto surge a Orientação profissional com finalidade de auxiliar o jovem no momento da escolha, sistematizando o processo para que o jovem descubra qual caminho prosseguir. Para simplificar a escolha, são indicados: o conhecimento de si mesmo; conhecimento das profissões; escolha propriamente dita.

O trabalho em grupo tem atingido bons resultados em sua pratica profissional, devido á necessidade do adolescente de estar inserido em grupos nessa fase de seu desenvolvimento.

Já o segundo capitulo, enfatiza a teoria da matriz da identidade, e o reconhecimento do eu que se forma a partir das vivências dos papéis psicossomáticos em três áreas: mente, corpo e percepção do ambiente. Através do psicodrama e a teoria dos papéis compete uma função muito importante no processo de Orientação Profissional e envolve a criatividade no papel de cada um nos trabalhos desenvolvidos pelo grupo onde os jovens vão poder experimentar através das dramatizações os diversos papéis profissionais e com isso estarão mais seguros para fazer suas escolhas e reconhecer o eu.

Para tanto, o capítulo três apresenta um relato da proposta de dissertação de mestrado em Educação na UFSC em 1993, por Dulce Helena Penna Lucchiari. O projeto se trata de um planejamento de Orientação Profissional compostos por oito encontros.

\footnotetext{
${ }^{1}$ Endereço eletrônico de contato: maisa.ribeiro01@gmail.com

Recebido em 19/09/2018. Aprovado pelo conselho editorial para publicação em 05/12/2018.
}

Julho, 2019; Vol. X(Supl1):52-58. 


\section{IIII Fórum de Debates Psicologia na Contemporaneïdade}

Dessa forma, o primeiro encontro tem como objetivo fazer com que os participantes se conheçam, levantando expectativas em relação á Orientação Profissional e estabelecendo que cada jovem é responsável por sua escolha, não havendo necessidade de ser concluída no final dos encontros. Utiliza técnicas de adivinhar quem é quem, representação através de colagens de expectativas em relação a Orientação Profissional, firmação do contrato de tempo e permissão para gravação das entrevistas e como tarefa de casa, fazer uma lista do que gosta e não gosta de fazer.

O segundo encontro, tem como objetivo aprofundar o conhecimento mútuo e de si mesmo, perceber características e propiciar uma primeira reflexão sobre as profissões. $\mathrm{Na}$ técnica do segundo encontro o coordenador fala sobre o passado, presente e futuro, conhecendo as vivências e as dificuldades dos jovens. Tarefa para casa preencher "frases para completar" da obra de Bohoslavsy.

Já no terceiro encontro, o intuito foi analisar a maturidade de escolha de cada um, conhecer a estrutura familiar e refletir sobre o trabalho. Nas técnicas serão discutidos os seguintes itens: escolhas passadas, família, trabalho. Como tarefa, o jovem é solicitado fazer uma lista de profissões universitárias e coletar informações sobre elas.

No entanto, no quarto encontro tem como objetivo: permitir o contato com muitas profissões, ter visão global sobre essas e esclarecer as semelhanças e diferenças de cada uma. Nas técnicas, comentar sobre a tarefa proposta, dividir o grupo em dois, escolher algumas das profissões citadas na tarefa, reunir os grupos por semelhança, apresentar as profissões escolhidas, solicita-se que os jovens escrevam as profissões que mais os interessaram, distribuir uma folha de papel com atividades (Zalavsky, 1979), e marcar com um X as atividades que gostaria de realizar e como tarefa entrevistar profissionais e visitar locais de trabalho

Quinto encontro foca em trabalhar vínculos afetivos, assinalar preconceitos e conhecer sobre cada profissão. Como técnicas, apresentar e explicar a representação dos cartões do encontro anterior, explicação dos motivos da lista sobre convidar ou não cada uma das pessoas para uma festa imaginária, proposta da dramatização da festa. $\mathrm{Na}$ tarefa, escolher cinco das profissões apresentadas para estudar.

Sexto encontro conota: vivência de profissões no contexto dramático, sentimentos e expectativas do vestibular e falar sobe a realidade da universidade. Como técnicas, escolher um participante para a dramatização de uma situação no trabalho, responder algumas perguntas direcionadas para vestibular e faculdade e comentário das perguntas. E na tarefa, visitar cursos, entrevistar professores e estudantes das áreas escolhidas.

Sétimo encontro aprofunda as vivências das profissões e avalia o crescimento do trabalho no âmbito pessoal e grupal. Como técnica é pedido que os participantes dramatizassem o que

Julho, 2019; Vol. X(Sup/1):52-58. 


\section{Fórum de Debates Psicologia na Contemporaneídade}

foi mais significativo e fizessem uma colagem sobre o seu desenvolvimento no grupo e posteriormente comentá-las. E na tarefa, preencher a ficha de autoavaliação e fazer uma redação sobre "quem sou eu?".

Oitavo encontro: entrevista individual que auxilia a imaginação do jovem no futuro, esclarece situações individuais e faz uma avaliação pessoal. Como técnica, trabalhar a redação feita pelo jovem, comentar aspectos que podem influenciar a escolha, analisa-se juntamente coordenador e jovem sobre a avaliação.

O quarto capítulo orienta o leitor o caminho para conceber o grupo de orientação profissional, enfatiza a utilização de técnicas com objetivo de planejar o grupo e através da criatividade desenvolvida poder criar algo novo.

O quinto capítulo discursa sobre o caso de uma garota chamada Patrícia, por volta dos vinte anos, filha de médico e que já havia tentado pela terceira vez o vestibular de medicina e não obteve sucesso. Procurou a Orientação Profissional, por não saber se realmente optaria pela medicina, se faz pelo pai, se escolheu ou foi escolhida. Com a participante foi utilizado diversas técnicas, onde apresentou falta de confiança, sentimentos de culpa e carência. Patrícia achava que fazer medicina seria sua melhor escolha, mas na verdade era o desejo de seus pais. Após passar por vários processos de Orientação Profissional Patrícia conseguiu conversar com seu pai sobre suas escolhas profissionais, o pai a entendeu e apoiou.

O sexto capítulo narra experiências que podem contribuir de forma significativa para profissionais que desejam trabalhar e estudar a Orientação Profissional.

O trabalho teve início com entrevistas individuais com cada participante, logo após foi realizado a apresentação para criar um clima mais amigável, em seguida fizeram duplas e foi aplicado algumas técnicas trabalhando a dificuldade da escolha e a impossibilidade de delegar a outros a nossa escolha. Solicitou ao grupo a criação de alguns cartazes retratando a relação do grupo e o futuro, através do feed-back foi possível refletir um pouco sobre as dúvidas angústias e expectativas, além de gostos e maneira de ser. No segundo momento aplicou-se a técnica do Role-playng, pretendendo trabalhar a questão dos preconceitos e estereótipos com relação às profissões. No último momento foram feitas discussões em torno da preparação de cada um, notando uma transformação no modo de pensar sua postura diante das questões trabalhadas em grupo. Em conjunto puderam redimensionar conceitos, valores, e posturas implicados no processo da escolha.

O capítulo sete expõe uma proposta de Orientação Profissional na escola de segundo grau. É na escola que os alunos deveriam ter a oportunidade de desenvolver suas potencialidades e crescimento psicológico e social, entretanto poucas tarefas são realizadas na prática, nas quais o aluno possa criar e gerar conhecimento a partir da sua própria experiência.

Julho, 2019; Vol. X(Sup/1):52-58. 


\section{IIII Fórum de Debates Psicologia na Contemporaneïdade}

De acordo com a obra alguns pontos teriam que ser abordados no decorrer do segundo grau: o conteúdo que deve ser feito a relação entre as disciplinas e as profissões, a relação homem trabalho de como ocorrem o interesse, a motivação e o prazer no trabalho, informação profissional o que são, o que fazem, onde, para quê, qual salário e oportunidades de formação nas profissões.

O Orientador Profissional nas escolas de segundo grau deve trabalhar no sentido de levar o aluno a ter clareza dos fatores que interferem em suas escolhas, elaborar projetos de vida que possam ser viabilizados a possíveis escolhas e ter conhecimento das realidades do mundo trabalho. A proposta de orientação profissional nas escolas possui dois momentos: o primeiro momento que trabalha a discussão sobre as escolhas profissionais e o segundo momento que trabalha com grupos pequenos de alunos aprofundando o processo de escolha assim como a liberdade de escolha e conhecimento de si mesmo no mundo do trabalho. E para finalizar é importante colaborar no sentido de diminuir os problemas relacionados as frustrações profissionais e é fundamental que se trabalhe com a Orientação Profissional nas escolas.

O capítulo oito discorre sobre o serviço de orientação profissional na Universidade de Santa Catarina e como se dá a escolha profissional no Brasil. Mostra dados que trazem uma grande preocupação com relação a qualidade da escolha feita por esses jovens, a motivação para os estudos e para a vida profissional.

$\mathrm{Na}$ Universidade de Santa Catarina, o serviço de orientação profissional é uma das atividades no Serviço de Atendimento Psicológico do Departamento de Psicologia e presta diversos tipos de atendimento à comunidade. Esse trabalho está estruturado da seguinte maneira: com divulgações, instruções, realização do trabalho são feitos os encontros de grupo, a avaliação dos trabalhos e por fim os comentários finais.

O capítulo nove conscientiza para as questões relacionadas à escolha profissional como uma abordagem integrada e apresenta premissas que embasam uma proposta, devido a alienação dos indivíduos que pertencem a instituições brasileiras e os consequentes fracassos. A partir da experiência de trabalho constaram nas práticas que; o compromisso com a educação torna-se cada vez menos valorizado por governantes e dirigentes de escolas particulares; o despreparo dos professores dos cursos de magistério e pedagogia; forte pressão por parte das escolas, da família e da sociedade para que o jovem opte por um curso universitário; não há valorização da escolha consciente da profissão; a desvinculação entre o que a universidade oferece e o mundo trabalho provoca uma realidade distorcida.

No desenvolvimento do trabalho, foi divido em três módulos; módulo 1-alunos adolescentes; módulo 2- instituição; módulo 3- pais. A partir de observações feitas no decorrer da pesquisa foi constatado o seguinte:

Julho, 2019; Vol. X(Sup/1):52-58. 


\section{IIII Fórum de Debates Psicologia na Contemporaneïdade}

- Despreparo no nível emocional nos três módulos;

- O desprezo pela autorealização como fator relevante na escolha da ocupação;

- A instabilidade econômica e sócio-política que desconsidera a perspectiva do futuro;

- A insegurança que gera frustração, decepção e obrigação frente ao trabalho;

- Desestimulação a aprendizagem;

- Alienação reforçada pelo consumismo compulsivo como forma de compensação das suas frustrações.

O capítulo dez expõe a segunda parte do livro, o contexto enfatiza a psicologia nos anos 90 , tratando de uma reflexão a respeito das práticas predominantes da psicologia no terreno da Orientação Profissional relacionado ao mercado de trabalho nessa época e as implicações da realidade produtiva no processo de escolha. No início da reflexão coloca se a questão da difícil interface entre o sistema educacional e a estrutura industrial que delimita espaços e práticas ocupacionais. Enquanto prática Psicológica seria desejável que a orientação profissional perdesse um pouco da sua conotação literal 'orientativa' para se assumir como processo de escolha do orientando, a escolha sugere mais autodefinição do que orientação, entende-se que o termo escolha profissional seja muito mais adequado para designar esses procedimentos. É importante citar a priorização de informações profissionais, pesquisa de profissões, 0 conhecimento das realidades de trabalho.

O capítulo onze pretende percorrer brevemente uma reflexão sobre a relação entre o mundo subjetivo (do sujeito) e o mundo objetivo (do trabalho). Deve-se pensar em um sujeito que existe dentro de determinadas relações sociais, não sendo possível compreender essas relações sem os sujeitos que a compõe. E o trabalho toda ação sobre a natureza com o objetivo de transformá-la de acordo com a necessidade, por esse trabalho o homem se apropria do mundo objetivo transformando a si mesmo.

O capítulo doze denota a orientação profissional junto a população, de maneira como vem sendo estruturada a vida urbana no Brasil é de essencial importância a participação de profissionais nas tomadas de decisões da comunidade em determinados assuntos que comprometem o bem-estar do indivíduo dependendo de temas como tecnologia, infraestrutura, saúde, educação e lazer. É importante dizer que a população tenha acesso ás possibilidades oferecidas através da organização comunitária.

Em se tratando da escolha profissional, volta-se ao favorecimento do bem-estar individual e coletivo no sentido do crescimento integral da pessoa e por possibilitar divisão do trabalho de modo a diversificar a produção em atendimento a população. Os esforços da Orientação profissional somados a outras ações da Psicologia representa grandes oportunidades para o aperfeiçoamento da qualidade de vida de indivíduos e coletividades.

Julho, 2019; Vol. X(Sup/1):52-58. 


\section{IIII Fórum de Debates Psicologia na Contemporaneïdade}

O capítulo treze implica sobre a criatividade e o exercício da profissão. A criatividade é considerada uma aptidão, está ligada á inovação, invenção e originalidade e ao nível da profissão cada contexto ganha tonalidades e contornos, ao mesmo tempo em que o indivíduo desempenha sua função transformando-a e recriando seu papel profissional social. Através desses aspectos é possível considerar que todo desempenho de função pode ser criativo, seja pelo movimento social que exige e coloca situações e problemas novos, seja pela busca de soluções novas para problemas antigos.

O capítulo quatorze reforça sobre a questão do vestibular. A porta de entrada para a universidade é o vestibular, para esses é feita uma prova de forma unificada que pretende 'medir' conhecimento dos candidatos e consequentemente alguns entram e outros tantos ficam de fora. O estudar para o vestibular chega a tornar uma neurose, muitos jovens nessa época nem saem de casa. De acordo com a autora o vestibular é um evento dissociado que não tem nenhuma relação com o que vem antes e com o que acontecerá depois. Muitos jovens fazem cursinho preparatório e os familiares estão dispostos a autos investimentos, mas as reprovações acabam criando inimizades até mesmo entre pais e filhos. Uma solução apresentada é que a seleção seja feita por sorteio, pois além de oferecer realmente iguais condições a todos os candidatos, teria de volta a amizade entre pais e filhos.

O tema da autora se volta para a Orientação Profissional, ela expõe trabalhos e sistematiza técnicas para que essas sejam um modelo a ser seguido para profissionais e estagiários que trabalhem nessa área.

Em sua obra a autora consegue discorrer o texto e seus contextos de forma objetiva e apropriada a sua proposta levantada inicialmente, sem incorrer em excessos e não deixando de considerar aspectos relevantes a Psicologia em sua ampla estrutura. O livro contribui essencialmente para os profissionais da Psicologia que atuam nessa área para que eles possam auxiliar de forma adequada os jovens no momento da escolha profissional e adultos que estão insatisfeitos profissionalmente e pretendam investir em nova carreira ampliando as perspectivas desses indivíduos, utilizando técnicas e recursos que promovam auto- conhecimento sobre as pontencialidades e debilidades de cada um., considerando preferencias e limitações e os fatores que interferem nesse processo.

Vale ressaltar que em ánalise da obra sugiro que a autora em sua brilhante carreira e criação de trabalhos na área dê continuidade e que de forma como escreveu a 'Pensando e Vivendo a Orientação Profissional' possa nos propiciar ainda mais conhecimentos através de obras recentes.

Esta obra apresenta a Orientação Profissional em suas diversas facetas, o que é e como fazer e onde fazer. Preocupa-se com a escolha profissional dos jovens através de grupos.

Julho, 2019; Vol. X(Sup/1):52-58. 


\section{IIII Fórum de Debates Psicologia na Contemporaneïdade}

Capacitam profissionais e estagiários na área da psicologia, propicia técnicas, planejamento e o uso do psicodrama como referencial teórico e prático, tornando possível sua aplicação no dia a dia.

Julho, 2019; Vol. X(Sup/1):52-58. 